\title{
Perfis visíveis na gestão social do desenvolvimento*
}

\author{
TÂNIA Fischer** \\ Vanessa Paternostro Melo*** \\ Mercya Rose de Carvallio**** \\ Ademário de Jesus $* * * * *$ \\ Renata Almeida Andrade****** \\ Claudiani Waiandt*******
}

SuMÁRIO: 1. Introdução; 2 . Organizações da sociedade civil como campo de práticas de gestão; 3. Gestão social: líderes no espaço e no tempo; 4. Perfis visíveis da gestão social: o Gapa-BA e o Via Magia como OSCs exemplares; 5 . Considerações finais.

S UMMARY: 1 . Introduction; 2 . Civil society organizations as a field for management practices; 3 . Social management: leaders in space and time; 4. Visible profiles of social management: Gapa-BA and Via Magia as exemplary civil society organizations; 5 . Final remarks.

\footnotetext{
* Artigo recebido em set. 2005 e aceito em jul. 2006.

** Doutora em administração, professora da Escola de Administração da Universidade Federal da Bahia, coordenadora do Ciags (Centro Interdisciplinar de Desenvolvimento e Gestão Social) e pesquisadora 1-A CNPq. Endereço: Av. Reitor Miguel Calmon, s/n, 3oandar - Vale do Canela — CEP 40.110-903, Salvador, BA, Brasil. E-mail: nepol@ufba.br.

*** Mestre em administração pela Universidade Federal da Bahia e pesquisadora do Ciags. E-mail: vpmelo@ig.com.br.

$* * * *$ Doutoranda em administração/Ucam-Canadá, mestre em administração pela Universidade Federal da Bahia e pesquisadora do Ciags. E-mail: mercya_carvalho@ig.com.br.

***** Graduando em administração e bolsista de iniciação científica do Pibic/CNPq vinculado ao Ciags. E-mail: ademariodejesus@yahoo.com.br.

$* * * * * *$ Graduanda em administração e bolsista de iniciação científica do CNPq vinculado ao Ciags. E-mail: renata_almeida@pop.com.br.

******* Doutoranda em administração pela Universidade Federal da Bahia, mestre em administração pela Universidade Federal do Espírito Santo. E-mail: cwaiandt@uol.com.br.
} 
Palavras-chave: gestão social; perfis; liderança.

KEY WORDS: social management; profiles; leadership.

Este artigo estuda a relação existente entre a gestão social do desenvolvimento, a performance de organizações da sociedade civil e o perfil de seus líderes. Para tanto, foram realizadas duas entrevistas, por meio da técnica da história oral, com dois gestores fundadores das respectivas organizações onde trabalham, situadas em Salvador e consideradas de reputação. Algumas questões nortearam o estudo qualitativo. Como a história de vida do seu principal gestor contribuiu para a organização ser o que é hoje? Como a sua história de vida se confunde com a história da organização? O que o levou a ser um gestor social e, mais especificamente, a fundar a organização? O que se vislumbra para o futuro da organização? Conclui-se que as organizações e seus gestores estão estreitamente imbricados e o sucesso das organizações reflete a trajetória bem-sucedida de seus líderes.

\section{Visible profiles in the social management of development}

This article studies the relations between the social management of development, the performance of civil society organizations and their leaders' profile. For that purpose two interviews using oral history technique were carried out with two CEOs who founded their respective well-reputed organizations in the Brazilian city of Salvador. The following issues guided the qualitative study: To what extent did CEO's life history contribute to the present status of the organization? In what sense is his life history tied with the history of the organization? What turned him into a social manager, and, more particularly, what led him to found the organization? What are the expectations concerning the future of the organization? Conclusions

point out that organizations and their managers are intimately imbricated, and that the success of organizations reflects the successful life history of their leaders.

\section{Introdução}

As organizações da sociedade civil (OSCs) são organizações paradoxais, controversas e enigmas recorrentes nas agendas de pesquisa. Elos importantes de conexões da sociedade civil, estado e mercado, as OSCs ocupam espaços intersticiais, ao mesmo tempo em que ganham identidade e se tornam peças estratégicas no jogo dos chamados poderes espacialmente localizados.

Definida pela autonegação e relativa exclusão do estado e do mercado (não-governamentais, não-lucrativas), as OSCs advogam autonomia, bem como 
a identificação com a ética do bem comum e o uso do espaço público como contexto de referência. Sua legitimidade deriva das ações que empreendem e do impacto que elas têm na sociedade civil em que se originam e que, de forma especial, espelham.

Têm o poder da auto-organização, da transformação de suas estruturas e estratégias e da regulação de seu próprio destino. Para isso, devem construir reputação e ganhar legitimidade. As de maior visibilidade na sociedade são valorizadas pela imagem construída e pelo perfil de seus gestores, além das dimensões substantivas de suas ações e da repercussão delas.

Foram delegadas funções de Estado e formas de representação social a essas instituições e elas foram elevadas à liderança, substituindo, em muitos casos, a representação direta dos movimentos sociais. São também interlocutoras importantes no campo das políticas públicas e das ações de desenvolvimento socioterritorial, daí a relevância deste artigo que contribui para a melhor compreensão dos poderes localizados no espaço e no tempo e para as formas de gestão social orientadas ao desenvolvimento territorial.

O universo das OSCs comporta muitos tipos de organizações e interorganizações, sendo muito diverso e fragmentado, de acordo com os resultados do mapeamento de 1.859 organizações da sociedade civil realizado em municípios baianos (capital e interior). Feito isso, considerou-se importante analisar, com maior profundidade, conjuntos organizativos delimitados e os perfis de liderança das organizações do conjunto - no caso gestores sociais. Um deles, objeto de estudo deste artigo, é representado por organizações de grande visibilidade, que têm reputação e gestores socialmente reconhecidos.

As organizações de caráter associativo, não-governamentais, não-lucrativos, conquistaram espaço entre sociedade e mercado, entre governo e sociedade e entre diferentes enclaves sociais.

São exemplares as intervenções e a gestão de OSG em projetos de escala local, regional e nacional financiados por recursos de fontes nacionais e internacionais. Os conjuntos integrados de projetos conformam-se em redes de socioeconomia solidária; nos chamados arranjos produtivos locais (especialmente em territórios de baixa densidade empresarial); em programas de desenvolvimento sustentável, geração de emprego e renda, de gênero e outros (Fischer, 2004).

Assim, adota-se, como pressuposto, que performance organizacional e liderança estão intimamente relacionadas. Na intenção de melhor compreender os fenômenos do poder e da gestão do desenvolvimento social, perguntase: como são estas organizações e qual é o perfil de seus líderes? Como são as trajetórias de sucesso e de que se derivam? Talentos especiais, vivências significativas, aprendizados formais, senso de oportunidade, habilidades de ges- 
tão tradicionais caracterizam estes perfis de liderança? Que traços têm estes líderes como gestores sociais do desenvolvimento? Como se articulam com a sociedade e o Estado? Como projetam a organização no futuro?

$\mathrm{Na}$ tentativa de responder a tais questões objetivou-se compreender a relação existente entre a performance de organizações da sociedade civil e o perfil de seus líderes.

Foi realizado um estudo quantitativo e qualitativo com uma amostra intencional de 12 organizações situadas em Salvador, consideradas de reputação, e cujos focos de atuação fossem distintos entre si. A fim de aprofundar a visão da dinâmica das organizações sociais e as várias etapas da trajetória dos líderes, a primeira etapa foi ampliada, com duas entrevistas por meio da técnica da história oral (Alberti, 1986) com dois gestores fundadores das respectivas organizações em que trabalham: o Grupo de Apoio e Prevenção à Aids da Bahia e a Casa Via Magia. Algumas questões específicas nortearam o estudo qualitativo. Como a história de vida do seu principal gestor contribuiu para a organização ser o que é hoje? Como a sua história de vida se confunde com a história da organização? O que levou a ser um gestor social e, mais especificamente, a fundar a organização? O que se vislumbra para o futuro da organização?

As entrevistas, transcritas integralmente, foram analisadas por meio de suas narrativas, buscando o sentido expresso do discurso dos líderes. O conteúdo de cada um desses textos foi analisado na perspectiva de entender como a projeção da organização é justificada pelo perfil dos seus líderes-fundadores. Assim, por meio de um recorte temporal, buscou-se compreender a história de vida dos líderes sociais e sua relação com a progressão do seu espaço territorial, e, por meio de um recorte espacial, entender os fatos, os momentos, as rupturas na vida desses líderes que contribuíram para explicar essa progressão.

O material transcrito foi organizado a partir de "códigos de processo" (Bodgan et al., 1994:225), comumente usados na ordenação das histórias de vida, que reúne frases que facilitam a categorização das seqüências de acontecimentos, mudanças ao longo do tempo ou passagens de um tipo ou gênero de estatuto para outro. Os códigos de processo apontam para períodos de tempo, estádios, fases, passagens, passos, carreiras e cronologia dos líderes entrevistados.

Este artigo estrutura-se de forma a refletir, inicialmente, sobre as organizações da sociedade civil como campo de práticas de gestão, para, a seguir, discutir a gestão social como processo de poder contingenciado pelas dimensões de espaço e tempo. Depois, é apresentada a história de vida dos dois gestores. As organizações agem no espaço local, legitimando-se pela capacidade 
de se articular em várias escalas de poder, pela consecução de metas de impacto na sociedade e, especialmente, pela capacidade de gestão de seus líderes, como veremos a seguir.

\section{Organizações da sociedade civil como campo de práticas de gestão}

As várias formas e estruturas organizacionais e interorganizacionais da sociedade civil têm seduzido pesquisadores no campo das ciências sociais em geral e dos estudos organizacionais em particular (Teodósio, 2001; Alves, 2002; Carvalho-Ferreira, 2004; Gohn, 1997; Meister, 1992; Sorj, 2004; Fischer e Melo, 2003; Fernandes, 1994; França Filho e Laville, 2004; Carvalho, 2000), entre muitas outras fontes.

A expressão ONG teve origem nas Nações Unidas, quando foi necessário distinguir as organizações representativas de governos das que, por mérito, deveriam ter assento na assembléia da entidade. A designação "terceiro setor" surgiu nos Estados Unidos, englobando todo o tipo de organizações sem fins lucrativos, o que é contestado por Fischer e Falconer (1998), dada a heterogeneidade do conjunto.

A expressão "não-governamental" remete a outros significados, que podem ser justificados pelas trajetórias das práticas e dos valores e ideologias característicos.

Herbert de Souza (Santana, 1992) aponta o período entre os anos 1960 e 1980 o marco do surgimento das organizações não-governamentais brasileiras, nascidas em função da luta política da sociedade civil contra o regime autoritário da ditadura militar, que se implantou em 1964. Nesse contexto, atuavam muito próximo da clandestinidade, ligadas a movimentos sociais de base, igrejas, movimentos sindicais e populares. Tinham uma ênfase claramente de oposição em relação ao governo, expressa na terminologia "não-governamental" (ONG), a que se agrega a expressão "não-lucrativa".

No processo de surgimento das organizações não-governamentais, também teve papel fundamental a influência de organismos internacionais. Medina (1997) observa que em 1950-60 organismos internacionais começaram a fomentar um processo de desenvolvimento comunitário em países do Terceiro Mundo, pressupondo níveis maiores de participação da comunidade. Os organismos internacionais legitimaram as organizações não-governamentais, pregaram a necessidade de apoio político e popular e o fortalecimento da administração local para concretização do plano de desenvolvimento. 
Além de contextualizar o papel dos organismos internacionais, Medina (1997) analisou o perfil das organizações não-governamentais ao longo do tempo na América Latina. Gohn (1997) também fez uma análise nesse sentido, voltada para a realidade brasileira, e coloca que, nos anos 1990, as ONGs ganharam importância por serem potenciais parceiras do poder político, em decorrência de sua estruturação. Essa relação de parceria passou a ser estimulada, uma vez que o discurso neoliberal pressupõe a retirada do Estado de uma série de atividades e a primazia do mercado. Ainda segundo Gohn (1997), nessa mesma época, houve uma reconfiguração do modelo de financiamento às ONGs, do assistencialismo à auto-sustentabilidade. Observa-se um fortalecimento das estruturas nacionais com a criação da Abong (Associação Brasileira de ONGs) e da CMP (Central de Movimentos Populares), bem como o desenvolvimento de movimentos internacionais no Brasil, a exemplo da ONG ambientalista Greenpeace.

O foco de ação das ONGs e dos movimentos sociais também sofreu mudanças: da luta por transporte, saúde, educação e moradia para a luta pela sobrevivência física (alimentos e terra); luta por moral e ética política; por direito à pluralidade (movimentos de gênero, raça e idade); por uma participação na política direta institucionalizada; perspectiva de parceria, não de oposição ao governo; e políticas formuladas para segmentos sociais. Gohn acrescenta que, apesar de apregoarem autonomia e independência em relação ao Estado, os fundos políticos permanecem como os grandes financiadores de suas demandas.

A atuação da sociedade civil organizada tomou um rumo diferente, voltado agora não mais para a luta contra o autoritarismo do Estado, como ocorria nos anos 1960-80, mas para a democratização da sociedade (Randolph, 1990, citado por Santana, 1992).

O foco de análise foi se ampliando e reflete a evolução das formas de ação coletiva conforme constatado nos estudos referidos, desenvolvidos na década de 1990 e início desta. Por exemplo, os movimentos sociais que operavam em Salvador no início dos anos 1990 eram de caráter vicinal, como a Associação dos Favelados, que tinha como escala de ação a cidade.

Registra-se, então, uma crise de representação e uma substituição gradativa dessas associações por organizações de caráter mais independente, que assumiram um papel mediador entre interesses da sociedade, governos e agências nacionais e internacionais. O contexto dos anos 1990 colocou em evidência as organizações da sociedade civil, provavelmente em decorrência das suas próprias conquistas e do fortalecimento da perspectiva de parceria entre as esferas do Estado, mercado e sociedade civil organizadas, sendo-lhes delegada a tarefa de construir "novas transversalidades entre espaços institucionais fragmentados" (Meister, 1992). 
As organizações não-governamentais afirmam-se na esteira de políticas sociais sugeridas pela Constituição de 1988. Na Bahia, as organizações não-governamentais tornaram-se protagonistas da cena social, assumindo funções na execução de programas e projetos de políticas públicas, de agentes financiadores nacionais e internacionais e como expressão e afirmação da etnicidade, como foi o caso dos grupos afro-culturais em Salvador. Tais grupos atraíram a atenção dos pesquisadores e se projetaram internacionalmente como organizações associativas e produtores da cultura com inserção em mercados internacionais, na década de 1990.

O Grupo Cultural Olodum foi estudado por Fischer e Dantas (1993) e por Dantas (1994), iniciando uma série de estudos sobre organizações da mesma natureza como o Ylê Aiyê, os Apaches do Tororó, as Organizações Brown, os Filhos de Gandhi (Ferraz, 2001). Esses trabalhos se apóiam no viés interpretativo de Siqueira (1993) que reconstrói especialmente os estudos sobre redes sociais.

Como se reitera, os poderes locais estão entrelaçados em estratégias orientadas tanto por competição e conflito de interesses, quanto por princípios e práticas solidárias, formas de gestão verificáveis em organizações complexas.

O reconhecimento da hibridização dessas organizações representativas de interesses contribuiu para a intensificação dos estudos sobre organizações complexas orientadas ao desenvolvimento socioterritorial.

Captando necessidades sociais intangíveis, dando espaço de palavra a novos atores, experimentando novas práticas e tecnologias sociais, criando comunidades de interesses e de aprendizagem coletiva, as organizações associativas da sociedade civil têm escalas variadas — da unitária à rede de movimentos, da escala microlocal à escala global, de estruturas das mais simples às mais complexas.

Como organizações de tipo ideal que procuram valorizar o seu papel, as ONGs estão sob controles sociais frouxos, sem instâncias de regulação definidas $a$ priori, comparativamente às organizações governamentais e empresariais.

Contradições e ambigüidade cercam as ONGs. Críticas são feitas ao seu papel marginal às estruturas de mercado, nelas intervindo como competidoras ao gerarem produtos e serviços ou às funções que exercem na gestão de políticas públicas, no momento em que há uma recentralização dos poderes de Estado no âmbito federal.

Institucionalizadas, as ONGs têm autonomia relativa, mas controle social precário. Não sendo lucrativas, devem ser sustentáveis e hoje se constituem em espaços de trabalho disputados por acadêmicos e gestores sociais. 
Talvez a dimensão mais contraditória e fascinante das OSCs seja o seu caráter de experimento social e organizacional, como incubadoras de práticas e matriz de novos desenhos institucionais.

Ao serem parte da sociedade que interpelam e combatem, são "marginais comprometidos", reificando o papel que ocupam nos vácuos institucionais, nas margens e nos interstícios interorganizacionais.

Organização que se afirma pela negação - não-governamental, nãoempresarial —, as ONGs são tão mais contraditórias quanto mais se integram a outras organizações constituindo interorganizações.

\section{Gestão social: líderes no espaço e no tempo}

De acordo com Fischer (2002): "A gestão é um ato relacional que se estabelece entre pessoas, em espaços e tempos relativamente delimitados, objetivando realizações e expressando interesses de indivíduos, grupos e coletividade".

A gestão adjetivada como social orienta-se para a mudança e pela mudança, seja de microunidades organizacionais, seja de organizações com alto grau de hibridização, como são as interorganizações atuantes em espaços territoriais micro ou macroescalares.

Múltiplas formas de poder são exercidas em diferentes escalas, na construção paradoxal e controvertida de utopias traduzidas em programas, projetos e ações de desenvolvimento que ocorrem em espaços territoriais e virtuais.

A espacialização do poder e a valorização da chamada esfera local têm articulado e fragmentado interesses de acadêmicos e não-acadêmicos, pois as questões de poder revelam-se no concreto, no cotidiano, na trama mais ou menos complexa das relações sociais. O poder é sempre assimétrico e pleno de tensões entre os que o exercem e os que o disputam. Se tem um caráter relacional recíproco, sugere também desequilíbrio e um jogo de forças com momentos de convergência e de antagonismo, de pactos e rupturas. Supõe liberdade e possibilidades de ação e zonas de incerteza que possibilitam recuos e proximidades.

Há alternância e multipolaridade nas relações de poder, especialmente do que já se denominou, singularmente, poder local. A transversalidade ou a complexidade das relações entre dominantes e dominados, com tensões, avanços e recuos permanentes, com ganhos e perdas reais e simbólicas que podem ser avaliados diferentemente conforme a perspectiva, faz com que se reconheça a crescente pluralidade do poder espacialmente localizado. Tratamos, então, dos poderes locais, analisados pelas teorias de ação coletiva, que aqui interessa na acepção de ação mobilizadora (Clark, 2000), de estratégia 
em processo (Martinet e Thiethart, 2001) caracterizada como tentativa de desenhar o futuro.

Friedberg (1997) diz que o estudo da dimensão organizacional da ação coletiva leva a considerar a estruturação de todo o contexto de ação como uma solução (ou respostas) específica que atores autônomos, agindo dentro das restrições próprias de uma racionalidade limitada, encontram formas de "confirmação conflitual" e geram "interdependência estratégica". Nesse caso, os contextos de referência são determinantes.

Contextos de referência estão delimitados por duas dimensões da vida humana: o espaço e o tempo. Portanto, o desenho de utopias em cenários futuros feito por atores sociais que detêm o poder está circunstanciado pelo tempo e pelo espaço. Ao desenhar utopias, as pessoas constroem organizações.

As estratégias e estruturas organizacionais são contingenciadas pelas variáveis espaço-temporais, e as "organizações e as pessoas que as lideram, também.

Administração e liderança são tratadas ora como construtos distintos, ora como áreas de interseção (Bryman, 1991; Lapierre, 1989).

Ao tratarmos de gestão social, articulamos liderança e management, eficácia, eficiência e efetividade social. Estamos tratando de mediações sociais realizadas por indivíduos (gestores) e suas organizações.

O campo de gestão social, ou de gestão do desenvolvimento social, é um reflexo das práticas e do conhecimento construído por múltiplas disciplinas, delineando-se uma proposta multiparadigmática, de natureza interdisciplinar. Como as ações mobilizadoras partem de múltiplas origens e têm muitas direções, as dimensões praxiológica e epistemológica estão entrelaçadas. Aprendese com as práticas, e o conhecimento se organiza para iluminar a prática.

A gestão do desenvolvimento é uma forma de gestão social, a transição entre modelos do século passado e novas formas, comprometidas com utopias de desenvolvimento local, que os tempos de crise fazem emergir.

$\mathrm{O}$ que caracteriza esse gestor, basicamente, além da capacidade de mediação, é a visão que precede qualquer ato de gestão. Vários autores falam da visão do líder. Da literatura pop management aos estudos mais consistentes sobre o indivíduo enquanto líder, a capacidade de ver, retrospectiva e prospectivamente, definem o presente organizacional.

March e e colaboradores (2003:155) recordam o mito de D. Quixote e colocam:

Como fornecer a aparição de visões capazes de transformar o curso das coisas? Para que a visão possa se realizar, deve-se encorajar a ação. As grandes ações vêm menos de existência de problemas que do sentimento de que se é capaz de mudar as coisas. 
Eugène Enriquez (1984:30) relaciona visibilidade de organização com a identificação de um caminho livre e novo, ainda não saturado.

Uma organização influente é aquela capaz de encontrar um caminho inédito... A definição do caminho depende do grupo que se quer influenciar (o governo, outros grupos, a cidade), o domínio sobre o qual se quer exercer influência (a fome, o modo de vida) e as formas de institucionalização que podem se tornar referência.

O saber-ver, essencial no design (Ferrara, 2002), é competência básica do gestor social.

As organizações sociais são focadas no desenho; estão sempre redefinindo significados e formas; de saber-ver, saber-fazer e saber-relacionar-se por meio de um projeto estratégico compartilhado: a organização.

Nesse contexto, a fim de compreender melhor a relação entre-perfil dos líderes e a performance da organização, apresenta-se a seguir análise da história oral de dois gestores sociais, cujas organizações possuem um alto nível de articulação interorganizacional, inclusive em nível internacional.

\section{Perfis visíveis da gestão social: o Gapa-BA e o Via Magia como OSCs exemplares}

Apresentamos aqui dados biográficos dos dois gestores e analisamos, por meio de técnicas de história oral, as trajetórias de ambos contextualizadas no espaço e no tempo. As visões que têm de si, dos outros, do mundo e da organização são mapeadas e discutidas.

\section{Trajetórias dos gestores sociais}

\section{A trajetória de Harley Henriques do Nascimento}

Nascido em 1968 na cidade de Campina Grande, Paraíba, Harley Henriques do Nascimento é o caçula de quatro irmãos. Quando tinha um ano de idade, sua família decide ir morar na cidade de Feira de Santana, interior da Bahia, local onde teve uma forte formação religiosa, chegando a fazer parte do Movimento Eclesiástico de Base e a ter uma participação representativa no grupo de jovens religiosos da cidade. Seu pai, comerciante, trabalhava viajando pelas cidades do interior do estado. Principal provedor da casa, responsável por manter o pa- 
drão da família de classe média a alta, sua figura foi muito marcante no sentido autoritário, rígido, austero, centralizador do poder e disciplinador até o momento em que, precocemente, veio a falecer (aos 40 anos de idade). A partir daí, sua mãe, antes apenas "cuidadora" dos filhos e dona-de-casa, se torna a principal provedora do lar, assumindo a ausência deixada pela morte do marido e mostrando-se um exemplo de coragem, força, determinação e inspiração para os filhos. Aos 15 anos de idade, Harley resolve "romper o cordão umbilical" e ir morar em Campina Grande, onde nasceu, para fazer o terceiro ano científico. Passa a residir com os avós maternos, mas sente a sua liberdade tolhida dentro do ambiente familiar e decide morar sozinho e se responsabilizar por seu sustento. A entrada para um grupo de teatro de grande projeção da Paraíba foi importante para a construção de vínculos de amizade muito fortes na época, pessoas com as quais chegou a dividir apartamento e despesas. Aí também acontece o despertar para os símbolos e a identificação com a cultura nordestina junto à necessidade de conquistar a sua completa independência financeira. Aprovado em dois vestibulares, um em Campina Grande e outro em Salvador, Harley opta pelo último, no intuito de resgatar o contato com sua família. No ingresso no universo acadêmico, surge a presença do movimento estudantil, do qual fez parte como ativista, e o convívio com estudantes de outras áreas como ciências sociais da UFBA (São Lázaro). Já nos primeiros anos como aluno do curso de administração de empresas, Harley vence a concorrência por uma bolsa de estudos concedida pelo Pólo Petroquímico de Camaçari, por meio do Instituto de Fomento Social do Pólo (Cofic) para estudantes de universidades particulares, o que garantiu a sua permanência em Salvador. Em 1988, com a sua iniciação sexual e a insatisfação com algumas limitações de muitos movimentos quanto às questões relacionadas ao indivíduo, Harley descobre o tema HIV/Aids, quando acontece a então chamada "mudança radical e revolucionária" na trajetória de sua vida. Diante da epidemia da doença na década de 1980, ele funda o Grupo de Apoio e Prevenção à Aids da Bahia (primeiro Gapa do Nordeste) e lhe confere dedicação exclusiva. A organização é concebida com o objetivo de assumir a Aids como um tema de desenvolvimento, não-emergencial e assume como missão: "educar o mundo a viver com a Aids". Trabalhar na influência de políticas públicas, oferecer assistência às pessoas infectadas/afetadas pelo vírus e oferecer educação para a prevenção foram os três pilares de sustentação iniciais da organização.

Em 1989, Harley abandona a faculdade no sétimo semestre e com o apoio da Oxfam — UK, o Gapa-BA inaugura a sua primeira sede. Ele vive uma experiência no presídio do Carandiru (SP) onde vivencia a realidade de soropositivos e é incumbido de repassar essa experiência como consultor do Ministério da Saúde para os presídios das principais capitais do Nordeste. Aí 
acontecem as primeiras dificuldades de gestão da organização. No ano de 1992, o Gapa-BA fecha parcerias com seis agências internacionais, momento em que a instituição dá um salto muito grande, porém identifica a necessidade de planejar-se e precaver-se dos riscos de depender exclusivamente de financiamentos internacionais. Em 1994, Harley parte para um estágio na Inglaterra e nos Estados Unidos, onde se apropria do conhecimento sobre sustentabilidade, mobilização e captação de recursos locais, estratégia de fortalecimento institucional definida para o Gapa-BA quando do seu retorno para o Brasil. Assim, o Gapa-BA demarca o seu momento de profissionalização e de projeção inicial. O Gapa-BA termina o ano com 14 parceiros internacionais financiadores e por meio das parcerias com a imprensa e com agências de publicidade, ele encontra espaço na mídia para passar a sua mensagem, com a veiculação de campanhas. No início da década de 1990 o Gapa estabelece a formação de redes e a sua participação em fóruns de representação como o Fórum Nacional de Direitos Humanos, o Conselho Municipal da Criança e do Adolescente, os Conselhos Estadual e Municipal de Saúde, o Comitê Nacional de Aids e o Comitê Nacional de Vacinas. A partir desse momento, o Gapa-BA fica conhecido nacional e internacionalmente e passa a atuar como consultor no tema de mobilização e captação de recursos. Aqui, identidades pessoal e organizacional se confundem e isso passa a incomodar Harley. A visão de futuro dele para a organização é estar presente, como "ponto de apoio" e de referência técnica para ONGs que trabalham no campo temático de HIV/Aids em países de língua portuguesa da África.

\section{A trajetória de Ruy Cezar}

Ruy Cezar nasceu em 1957 em Tesouras (antigo distrito de Ipiaú), atual município de Ibirataia, na Bahia. Foi um típico garoto do interior, com família grande (sete filhos) e bem estruturada e que viveu com uma certa estabilidade; ele era o terceiro filho mais velho. Ao longo da sua infância, percebe-se que o mesmo possuía a angústia de quem gostaria de alçar vôos mais altos. A criatividade, a curiosidade e a introspecção sempre foram suas características durante esse período. Por conta dessa postura tinha uma certa dificuldade de se relacionar com as outras crianças; não gostava de competir com os outros, mas sim de construir outras realidades, de fantasiar. Com o tempo, houve a mudança para a cidade de Ipiaú e logo depois o ingresso na escola agrícola Emarc (Escola Média de Agricultura da Região Cacaueira) no município de Uruçuca (BA), onde a adolescência chegou. Com ela, veio a entrada no mundo masculino por meio do esporte (basquetebol). Além disso, vieram as primeiras experiências no tea- 
tro e na produção de textos que lhe deram a possibilidade de criar os primeiros vínculos de amizades; nesse percurso também teve contato com obras e construções que representavam o inconformismo naquela época. Ruy Cezar também viveu o sentimento de querer mudar a realidade que acometia a sua família quando adolescente: uma crise econômica que obrigou seus pais a mandarem os filhos mais velhos estudarem fora; Ruy era um deles. Depois da experiência na escola rural, onde aprendeu um ofício, Ruy Cezar alcança relativa estabilidade, podendo ajudar a família, mas, para surpresa dos pais, resolveu tentar a vida em Salvador, fazendo vestibular para comunicação na UFBA em 1977. A partir daí, houve um processo brusco de mudança de vida para ele, que rapidamente entrou no movimento estudantil e pelo seu carisma tornou-se presidente do DCE da UFBA e logo depois líder estudantil responsável pela reconstrução da UNE em 1979. Teve oportunidade de viajar pelo país e pelo mundo, conhecendo culturas e muitos brasileiros exilados no período da ditadura militar. Participou de todos os processos e ações de luta contra a ditadura militar, muitas vezes liderando-as. É bom frisar que desde a participação em um grupo de teatro na adolescência, o militante estudantil Ruy nunca mais largou o teatro. As muitas experiências no movimento estudantil fizeram com que Ruy Cezar tivesse outra angústia: tanto a ditadura militar, quanto a esquerda no Brasil e no mundo tolhiam a individualidade e a dimensão comportamental. Com essa conclusão, Ruy tomou a decisão de sair da política e mergulhar no universo que diz respeito à expressão da individualidade e do entendimento de si mesmo e do outro, por meio da educação e cultura. Mais uma vez, Ruy contraria seus pais, que pensavam que teriam um filho político, e a esquerda brasileira, que já contava com um novo líder. Por conta disso, Ruy Cezar muda-se com sua esposa, Rose Reyas, para São Paulo em 1982 e como resposta a esse questionamento cria, junto com Rose e mais alguns colaboradores, o grupo de teatro Via Magia. O interesse não era só o teatro, mas a educação também. Por isso, dois anos depois (1984), houve o interesse de retornar para Salvador e iniciar um projeto próprio na área de educação. O Instituto Casa Via Magia congregava educação e teatro e veio para ser um espaço de construção e difusão de idéias e práticas baseadas no construtivismo. O projeto foi recebido com estranhamento pela sociedade soteropolitana, mas logo ganhou espaço, por ser alternativo e de interesse de vários pais da classe média que fizeram parte do movimento estudantil. Por conta disso, a escolha estratégica da organização foi se lançar para fora da Bahia e do Brasil, intercambiando experiências com artistas e grupos de outros países já no final da década de 1980. Em 1991, criou-se a Rede LatinoAmericana de Arte e Cultura e a partir daí houve o processo de internacionalização da instituição que, trabalhando em redes, tornou-se mais reconhecida no exterior do que no Brasil, especialmente na Bahia. Além da opção de trabalhar 
em redes, a Via Magia trouxe como prática a busca pela inovação em todos os seus projetos, ganhando uma reputação internacional na área de cultura. A instituição foi a coordenadora executiva do primeiro Fórum Cultural Mundial em São Paulo (2004), sob a liderança de Ruy Cezar. Atualmente, a organização e o líder pretendem se voltar mais para o local (Federação, Salvador-BA), por considerar que houve um distanciamento entre a própria Via Magia e o seu local. Além disso, a perspectiva de futuro é sistematizar todas as informações e experiências da instituição, para repassar a outras organizações, tornando-se uma referência no Brasil e no mundo.

\section{História oral de dois líderes baianos}

Os quadros 1 e 2 buscam sintetizar a trajetória dos dois gestores sociais no tempo e no espaço, para posterior análise.

\section{Quadro 1}

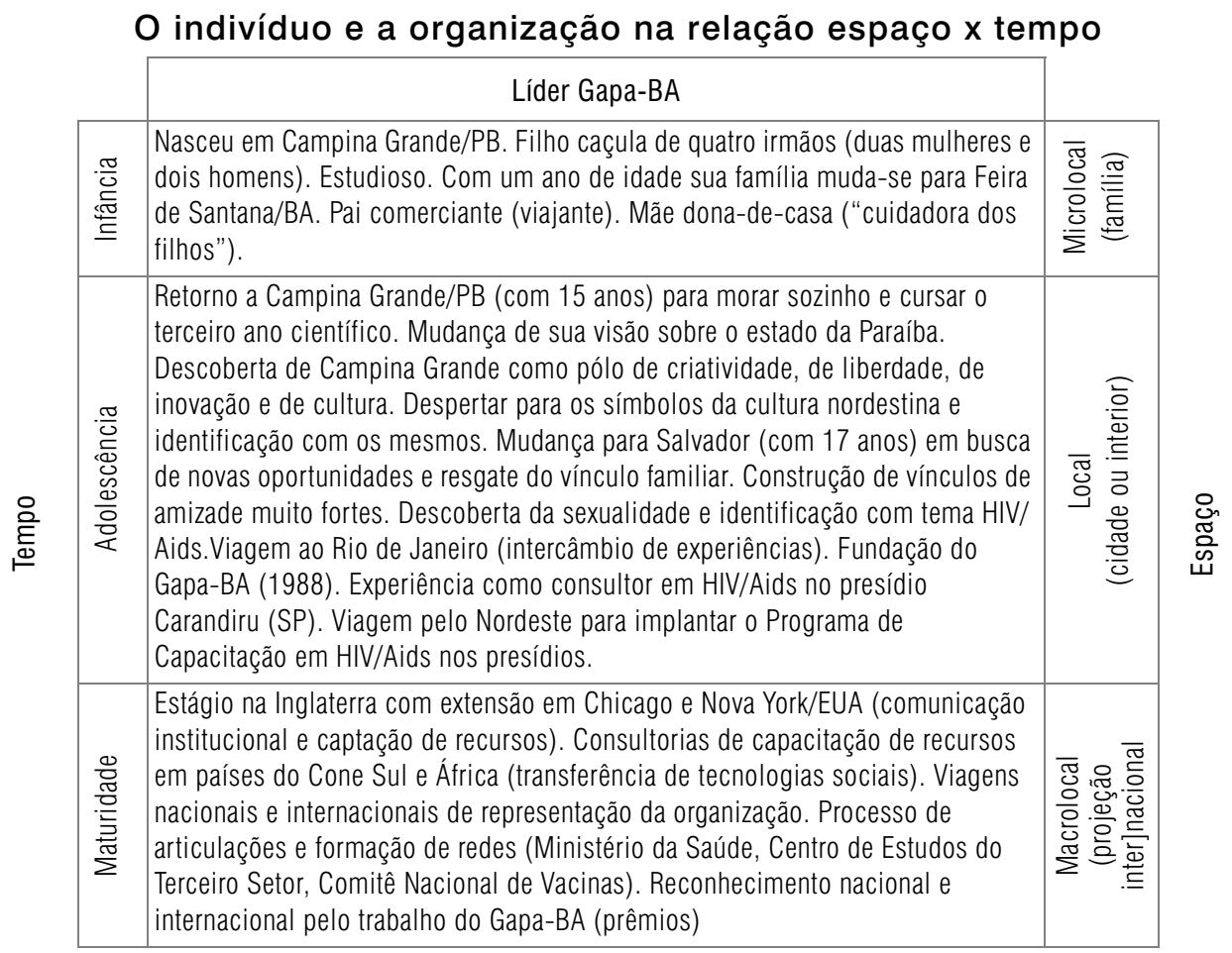




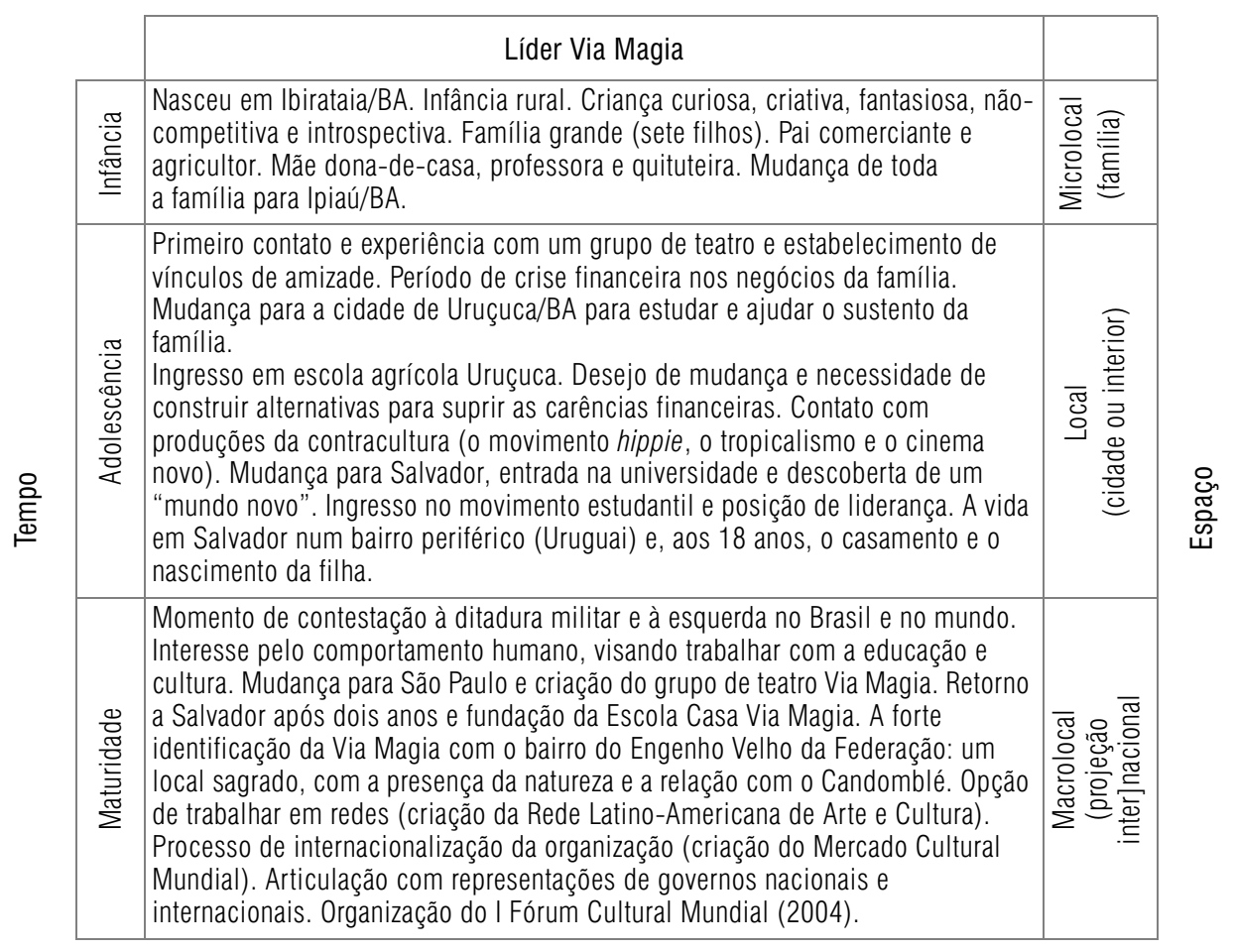

Como se constata, os dois gestores são de origem interiorana, tendo vivido significativas experiências na infância, junto ao núcleo familiar, e na adolescência, como militantes do movimento estudantil. Acompanhando a progressão do tempo, deslocam-se da escala local (municipal) para a nacional e internacional. Evidencia-se a relação estreita entre a construção organizacional e a ampliação do espaço de ação. Quanto maior a visibilidade, mais ganho de escala nacional e internacional.

A figura expressiva e forte das mães diante do papel mais diluído da figura paterna são convergentes nas duas trajetórias. A auto-referência como crianças criativas, determinadas e contestadoras também, bem como a valorização das origens. A visão do mundo como "socialmente injusto", bem como dos outros como conservadores, com exceção dos jovens, que seriam agentes potenciais de transformação, pode explicar a origem de suas organizações, orientadas fortemente à transformação social. As referências de ambos coincidem quanto a líderes criativos, transgressores e revolucionários. O líder do Gapa-BA cita organizações como referência, além de pessoas. Não por acaso, tem formação em administração. O líder do Via Magia cita pessoas e referências intelectuais na política, teatro e educação, com formação em comunicação. 


\section{Quadro 2}

\section{Características dos líderes}

\begin{tabular}{|c|c|c|c|}
\hline \multicolumn{2}{|c|}{ Dimensões } & Líder 1 - Harley & Líder 2 - Ruy Cezar \\
\hline \multirow{2}{*}{ 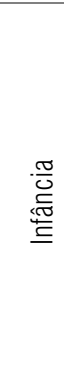 } & 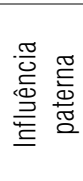 & $\begin{array}{l}\text { Comerciante — viajava muito. Figura } \\
\text { marcante: mentor, rígido, disciplinador, } \\
\text { centralizador do poder, provedor do lar. } \\
\text { Preocupação com a educação e orientação. } \\
\text { Morte precoce ( } 40 \text { anos). }\end{array}$ & $\begin{array}{l}\text { Agricultor. Figura ausente. Passivo para as } \\
\text { questões familiares. Pouco afetivo. }\end{array}$ \\
\hline & 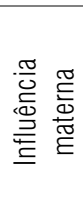 & $\begin{array}{l}\text { Dona-de-casa e "cuidadora" dos filhos. } \\
\text { Forte formação religiosa transmitida. } \\
\text { Assume o papel de provedora/mantenedora } \\
\text { do lar com a morte do marido. Espírito } \\
\text { empreendedor. Imagem de uma mulher forte } \\
\text { e inspiradora. }\end{array}$ & $\begin{array}{l}\text { Uma pessoa vibrante e angustiada. Figura } \\
\text { milagrosa e transformadora. Imagem de } \\
\text { mulher solucionadora de problemas, } \\
\text { heroína. Dialogava sobre questões } \\
\text { existenciais. Uma mulher bonita e alegre. }\end{array}$ \\
\hline \multirow{4}{*}{ 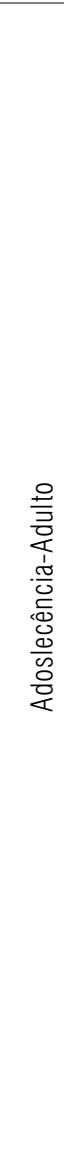 } & 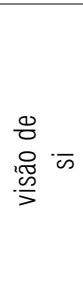 & $\begin{array}{l}\text { De criança rebelde a adolescente } \\
\text { disciplinado e aluno exemplar. Ser humano } \\
\text { tolhido pelas limitações do espaço. } \\
\text { Desbravador, determinado, corajoso, } \\
\text { gostava de arriscar a vida. Orgulho por ser } \\
\text { nordestino. Ser humano independente e } \\
\text { responsável por si mesmo. Jovem } \\
\text { preocupado com questões sociais. } \\
\text { Sentimento de grupo. }\end{array}$ & $\begin{array}{l}\text { Uma criança curiosa, criativa, não- } \\
\text { competitiva, fantasiosa e introspectiva. Um } \\
\text { adolescente contestador e inconformado. } \\
\text { Uma pessoa inovadora e angustiada. Uma } \\
\text { pessoa orgulhosa pela sua origem e } \\
\text { trajetória. Preocupado com questões } \\
\text { existenciais. Defensor da expressão da } \\
\text { individualidade. Preocupado com o outro. } \\
\text { Um indivíduo polêmico e persistente. }\end{array}$ \\
\hline & 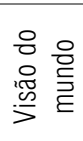 & $\begin{array}{l}\text { Eterna descoberta. Visão otimista e curiosa. } \\
\text { Predileção e crença nos estudos. Libertador } \\
\text { e oportuno. Muito além do conhecido, } \\
\text { trivial. Limitado, conservador, radical. }\end{array}$ & $\begin{array}{l}\text { Extremamente desigual. Hegemonia } \\
\text { econômica e cultural dos países do } \\
\text { Hemisfério Norte (Europa-EUA). Muito } \\
\text { competitivo. Mundo masculinizado. }\end{array}$ \\
\hline & 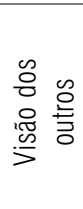 & $\begin{array}{l}\text { Ultrapassados, conservadores e limitados } \\
\text { em relação a alguns aspectos. }\end{array}$ & $\begin{array}{l}\text { Conservadores. Tolhidos. Jovens como } \\
\text { agentes transformadores. Angustiados. } \\
\text { Prepotentes e copiadores (indivíduos do } \\
\text { Norte). Criativos e com necessidade de } \\
\text { dialogar entre si, baixa auto-estima } \\
\text { (indivíduos do Sul). }\end{array}$ \\
\hline & 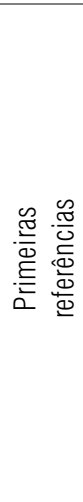 & $\begin{array}{l}\text { Universo acadêmico (curso de } \\
\text { administração de empresas). Movimento } \\
\text { Eclesiástico de Base e grupos de jovens } \\
\text { religiosos. Grupo de teatro da Paraíba. } \\
\text { Movimento estudantil (contato com alunos } \\
\text { do curso de ciências sociais da UFBA). } \\
\text { Herbert Daniel (intelectual do Movimento } \\
\text { Gay e ativista do tema HIV/Aids). Paulo } \\
\text { César Bonfim (Gapa-SP). Renato Russo, U2 } \\
\text { e Madonna (míticos). Dra. Lair Guerra } \\
\text { (programas de pesquisa em HIV/Aids junto } \\
\text { com o governo). Admiração por figuras } \\
\text { revolucionárias, transgressoras. } \\
\text { Organizações não-governamentais } \\
\text { reconhecidas do eixo Rio-São Paulo. }\end{array}$ & $\begin{array}{l}\text { Infância: mãe e pai; professoras e Tarzan } \\
\text { (o homem da selva, assim como ele). } \\
\text { Adolescência e adulto: os tropicalistas } \\
\text { (Caetano Veloso e Gilberto Gil); escritores } \\
\text { (Graciliano Ramos, Guimarães Rosa, } \\
\text { Krisnamurti, Jorge Eldado e José Lins do } \\
\text { Rego). Na universidade: professores (Rui } \\
\text { Espinheira Filho, Fernando Passos, Emiliano } \\
\text { José e Albino Rubim). Referências políticas: } \\
\text { Karl Marx e Nietzsche. Referência no teatro: } \\
\text { Augusto Boal, Brecht e João Augusto } \\
\text { (diretor do teatro livre da Bahia e um dos } \\
\text { fundadores do Vila Velha. Referência na } \\
\text { educação: Paulo Freire. }\end{array}$ \\
\hline
\end{tabular}




\begin{tabular}{|c|c|c|c|}
\hline \multicolumn{2}{|c|}{ Dimensões } & Líder 1 - Harley & Líder 2 - Ruy Cezar \\
\hline 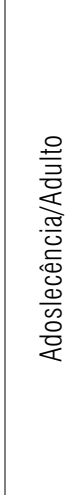 & 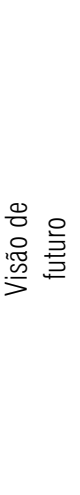 & $\begin{array}{l}\text { Pensar a organização estrategicamente (para } \\
\text { além do campo HIV/Aids e do espaço local } \\
\text { — Salvador/BA). Projeto de consultoria ou } \\
\text { sistema de apoio em captação/mobilização } \\
\text { de recursos em países de língua portuguesa } \\
\text { da África ("perspectiva da solidariedade } \\
\text { internacional"). Ser um referencial técnico } \\
\text { para outras organizações sociais do Brasil e } \\
\text { do mundo. Poder atuar em outras esferas do } \\
\text { campo social. Servir de referência e de } \\
\text { inspiração para outros líderes sociais. Poder } \\
\text { dar continuidade à sua formação } \\
\text { profissional. }\end{array}$ & $\begin{array}{l}\text { Necessidade de transmitir o produto das } \\
\text { experiências para os outros. Necessidade de } \\
\text { trabalhar mais localmente (Federação, } \\
\text { Salvador/BA). } 0 \text { Brasil e a Via Magia têm } \\
\text { possibilidades enormes de se colocarem } \\
\text { num lugar especial no mundo. Um lugar que } \\
\text { representa um convívio fraterno, da } \\
\text { diversidade, novo, com novas idéias, } \\
\text { estéticas e práticas. }\end{array}$ \\
\hline
\end{tabular}

Depois de construída a organização (saber-fazer), os líderes do GapaBA e Via Magia expressam o desejo de ser referenciais para o Brasil e para o mundo. Almejam ganhar mais visibilidade e ampliar o raio de ação da organização, tornando-a nó de conexões locais, nacionais e internacionais. Consideram a organização "um lugar especial no mundo" e desejam ganhar mais território sem perder a ancoragem local. Expressam, também, um desejo de perpetuar sua trajetória por meio de ações, pessoas e produtos socialmente relevantes.

\section{Considerações finais}

Após a análise das organizações e da trajetória de seus gestores, reiteram-se pressupostos sobre a gestão social do desenvolvimento expressos nas considerações que fizemos.

Primeira consideração: a gestão social do desenvolvimento é um processo de mediação transformadora, que demanda competências construídas ao longo da trajetória de vida dos gestores. Os espaços em que viveram na infância e adolescência (a casa, o entorno, a cidade) são contextos de referência estruturantes das organizações que construirão no futuro.

Segunda consideração: as organizações da sociedade civil podem ser agentes de transformação determinantes em seus contextos de referência quando geridas por líderes com visão de si, dos outros e do mundo em que vivem, de modo a desenhar organizações com sentido estratégico. O desenho estratégico de organizações sociais deve considerar a articulação de múltiplas escalas de poder individual e societal; a construção progressiva e obstina- 
da de organizações que evoluem para articulações interorganizacionais de complexidade crescente; a provisão e o gerenciamento de recursos; a prestação de contas à sociedade e a avaliação e recriação da própria estratégia processual.

Terceira consideração: a gestão das organizações associativas, frágeis enquanto instituições que vivem em interstícios, depende da gestão do simbólico, do valorativo, do culto da imagem e das representações. Assim, a organização e seu líderes se confundem em muitos momentos, sendo a organização um espelho narcísico. A trajetória dos gestores bem-sucedidos em seus papéis de liderança envolve engenho, arte e um desejo intenso de irradiação e perpetuação do poder da organização pelos seus produtos e pelos seus impactos.

Quarta consideração: a gestão de organizações associativas para ser legítima deve ser eficiente e, para tanto, deve se legitimar, criando círculos virtuosos na lógica social que orienta a ação.

Quinta consideração: as influências determinantes na trajetória dos gestores parentais ou comunitárias são embebidas em contextos de referência valorativos e ricos em significado. A estas, agregam-se outras referências culturais ao longo da vida que definirão rumos conforme sua natureza (artísticas, políticas e filosófica).

Finalmente, conclui-se que uma boa performance organizacional está diretamente imbricada com a gestão. Ser gestor em organizações sociais requer condições especiais de liderança, relativamente às exigências de organizações empresariais e governamentais, mais delimitadas como modelos burocráticos.

A gestão social do desenvolvimento é tarefa compartilhada entre esferas da sociedade vistas como totalidade. Neste artigo, focalizamos uma das formas organizacionais - as organizações da sociedade civil - e a trajetória de vida de dois gestores, na tentativa de contribuir para a construção de perfis para a gestão social. O que tais perfis sugerem, no discurso dos gestores, pode ser bem mais significativo do que podemos ver.

\section{Referências bibliográficas}

ALBERTI, V. História oral. Rio de Janeiro: FGV, 1986.

ALVES, Mário Aquino. Terceiro setor. O dialogismo polêmico. 2002. Tese (Doutorado em Administração) — FGV/Eaeso, Fundação Getulio Vargas.

AVENIER, M. J. La stratégie chemin faisant. Paris: Economica, 1997.

BOGDAN, R. C.; BIKLEN, S. K.; BAPTISTA, T. M. Investigação qualitativa em educação. Portugal: Porto Editora Ltda., 1994.

BRYMAN, A. SCS as a model for research into organizational culture. In: FROST, P. et al. Refraiming organizational culture. Londres: Sage, 1991.

Rap Rio de Janeiro 40(5):789-808, Set./Out. 2006 
CARVALHO, Cristina Amélia Pereira. A transformação das ONGs no Brasil: um processo de isomorfismo com as ONGs do Norte. In: ENCONTRO NACIONAL DE ESTUDOS ORGANIZACIONAIS, Recife, 2000. Anais... Recife: Observatório da Realidade Organizacional, Propad/UFPE, Anpad.

CARVALHO-FERREIRA, J. Les potentialitès de developement du troisiene secteur dans les societès contemporaines. Comunicação apresentada no AISLF. Tours, França, 2004.

CASTRO, Rocío C. Genero-etnia-classe: reflexión sobre la genealogía del poder a partir del estudio de las mujeres negras en Salvador. In: SIMPOSIO Género en la Región Subandina, Cochabamba, 1998.

CLARK, P. Organizations in action. Londres: Routledge, 2000.

DANTAS, Marcelo. Olodum: de bloco afro a holding cultural. Salvador: Olodum, Fundação Casa de Jorge Amado, 1994.

ENRIQUEZ, E. Les figures du maître. Paris: Arcantiére, 1984.

FERNANDES, Rubem César. Privado porém público. O terceiro setor na América Latina. Rio de Janeiro: Relume-Dumará, 1994.

FERRARA, L. F. Design em espaços. São Paulo: Rosari, 2002.

FERRAZ, Aparecida; FISCHER, Tânia. Liderança e mediação de identidade: a palavra dos líderes e a voz da mídia. In: ENCONTRO NACIONAL DA ASSOCIAÇÃO NACIONAL DE PÓS-GRADUAÇÃO EM ADMINISTRAÇÃO 25., Campinas, 2001. Anais... Campinas: Enanpad 2001. CD-ROM.

FISCHER, T. (Org.). Poder local: governo e cidadania. Rio de Janeiro: FGV, 1993. p. 164-176.

. Organizações e interorganizações na gestão do desenvolvimento socioterritorial. Organizações e Sociedade, Salvador, v. 11, p. 13-41, 2004. (Edição especial).

; DANTAS, Marcelo. Groupe Culturel Olodum - la stratégie des acteurs. In: CONFERÉNCE SUR LE MANAGEMENT DES ARTS ET LA CULTURE, 2., França, 1993. Annales... v. 2, França, 1993.

. Poderes locais, gestão e desenvolvimento. Salvador: Casa da Qualidade, 2002.

; MELO, Vanessa P. Gestão social do desenvolvimento e interorganizações. In: COLÓQUIO INTERNACIONAL SOBRE PODER LOCAL, 9. Salvador, 2003. Anais... Salvador, 2003.

—- TEIXEIRA, Ângela. Réseaux sociaux, citoyenneté et gestion publique à Salvador, Bahia. In: CONFERENCE EUROPÉENNE SUR L'ANALYSE DES RÉSEAUX SOCIAUX, 2., Paris, 1991. Ammales... Résumés des Communications: Abstracts, p. 68-69, Paris, 1991.

FRANÇA FILHO, G.; LAVILLE, Jean Louis. A economia solidária numa perspectiva internacional. Rio Grande do Sul: UFRGS, 2004. 
FRIEDBERG, E. Le dynamique de l'action organisée. In: CABIN, P. Les organisations — état des savoirs. Paris: PUF, 1997.

GOHN, Maria da Glória. Movimentos sociais e ONG’s no Brasil na era da globalização. In: - Teoria dos movimentos sociais. Paradigmas clássicos e contemporâneos. São Paulo: Edições Loyola, 1997.

LAPIERRE, L. Imaginário, administração e liderança. Revista de Administração de Empresas, São Paulo, v. 29, n. 4, p. 5-16., out./dez 1989.

MARCH, James-G; WEIL, Thierry; THOENIG, Jean-Claude. Le leadership dans les organisations. Paris: Les Presses, 2003.

MARTINET, A.; THIETHART, R. Stratégies. Actualités et future de la recherche. Paris: Vuibert, 2001.

MEDINA, Miriam. Participação e espaço urbano no contexto colombiano. 1997. Dissertação (Mestrado em Arquitetura e Urbanismo) - Faculdade de Arquitetura e Urbanismo, Universidade de São Paulo, São Paulo.

MEISTER, A . Vers une sociologie des associations. Paris Economie et Humanisme. Ouvrière, 1992.

SANTANA, Maria das Graças Firpo Sandes. Organizações não-governamentais no Brasil: um estudo de caso. 1992. Dissertação (Mestrado em Administração) — Escola de Administração, Universidade Federal da Bahia, Salvador.

SIQUEIRA, Maria de Lourdes. As dimensões organizativas da cultura afro-baiana. In: FISCHER, Tânia (Org.). Poder local: governo e cidadania. Rio de Janeiro, 1993. v. 1, p. 164-175.

SORJ, B. A democracia inspirada. Rio de Janeiro: Jorge Zahar, 2004.

STRATI, A. Organization studies. Theory and method. London: Sage, 2000.

TEODÓSIO, Armindo dos Santos de Sousa. Pensar o terceiro setor pelo avesso: dilemas e perspectivas da ação social organizada na gestão pública. In: ENCONTRO DA ASSOCIAÇÃO NACIONAL DE PROGRAMAS DE PÓS-GRADUAÇÃO EM ADMINISTRAÇÃO, 25., Campinas, 2001. Anais... Campinas: Anpad, 2001.

VILLASANTE, T. R. Metodologia dos conjuntos de ação. In: FISCHER, T. (Org.). Gestão contemporânea. Cidades estratégicas e organizações locais. Rio de Janeiro: FGV, 1996. 